\title{
An Analysis of Energy and Carbon Intensities and Exergy Efficiency in Natural Gas Combined-Cycle Power Plants: A Case Study of Thailand
}

\author{
Yada Bunyamanid $^{1}$, Nantamol Limphitakphong ${ }^{3}$, Orathai Chavalparit ${ }^{1,3}$ and Thanapol Tantisattayakul ${ }^{2}$ \\ ${ }^{1}$ Department of Environmental Engineering, Faculty of Engineering, Chulalongkorn University, Bangkok 10330, Thailand \\ ${ }_{2}^{2}$ Faculty of Science and Technology, Thammasat University Rangsit Campus, Bangkok 12121, Thailand \\ ${ }^{3}$ Research unit of Environmental Management and Sustainable Industry, Faculty of Engineering, Chulalongkorn University, Bangkok \\ 10330, Thailand
}

\begin{abstract}
The objectives of this study were to estimate energy and carbon intensities of natural gas combined-cycle power plants and to improve the energy efficiency of power plants through an exergy analysis. Three plants in Thailand were evaluated as case studies in this research using data collected in $2013-2014$. The results showed that the average carbon and energy intensities of three Combined-Cycle Power Plants were $0.436 \mathrm{~kg} \mathrm{CO}_{2} / \mathrm{kWh}$ and 7.995 $\mathrm{GJ} / \mathrm{MWh}$, respectively. The range of the energy intensity in this study was slightly lower than that of other studies; however, the results of the carbon intensity were in the same range. The result of the exergy analysis illustrated that Heat Recovery Steam generator (HRSG) has the greatest exergy destruction due to the wide temperature range. To summarize, natural gas combined-cycle power plants require less energy and emit less carbon compared to other technologies or fuels. The exergy efficiency of HRSG was $60 \%$, with an exergy destruction rate of $66.88 \mathrm{MW}$. One approach to improve the efficiency of power plants is to improve the efficiency and performance of HRSG.
\end{abstract}

\section{Introduction}

Global warming, which is caused by increasing greenhouse gas emissions, is mainly the result of human activities. Scientific studies have found that greenhouse gas emissions have increased abruptly over the last few decades. Increasing attention has been paid to finding methods for reducing greenhouse gas emissions. In Thailand, for example, policies related to climate change have been established, such as the climate change model scheme of 2015-2050; its main target is to reduce energy consumption and greenhouse gas emissions, mainly in the energy and transportation sectors [1]. The sector that accounts for the highest emissions in Thailand is the energy sector, with $69.6 \%$ of the total emissions in 2000 . Within the energy sector, the energy industry has contributed the greatest amount of greenhouse gas emissions (approximately 41.7\%) [2]. Furthermore, in 2014, according to the report of the Energy Policy and Planning Office, Ministry of Energy of Thailand, the electricity generation industry accounted for the highest emissions $(40.1 \%)$ of the total energy sector emissions [3]. The indicators commonly used in many industries for evaluating the energy efficiency and environmental impact in terms of greenhouse gas emissions of plant operations are energy intensity and carbon intensity, respectively. Studies and reports have been conducted regarding the energy and carbon intensities in various industries, including the steel $[4,5]$, petrochemical [6], and electrical generation [7-9] industries.

Approximately $80 \%$ of electricity generation in Thailand currently depends on fossil fuels, which includes electricity generated from Combined-Cycle Power Plants (CCPPs) and thermal power plants, which account for $64.85 \%$ and $13.36 \%$ of the total installed capacity, respectively [10]. The CCPP is an energy efficient form of power generation that applies both Brayton (gas turbine) and Rankine (steam turbine) cycles to obtain higher thermal efficiency in comparison with individual steam or gas turbine cycles [11]. The gas-fired generation in California improved thermal efficiency more than $17 \%$ during 2001-2013 by introducing new CCPPs to the portfolio of natural gas power plants [12]. The analysis of carbon intensity of the electricity generation industry (fossil fuel power plants) in Thailand during 2004 - 2009 showed that CCPPs yielded the lowest carbon intensity of $0.426 \mathrm{kgCO}_{2} / \mathrm{kWh}$ compared to using other technologies or fuels [7]. The analysis of energy intensity in 2014 also presented consistent results in that natural gas CCPPs had the lowest energy intensity of $7.970 \mathrm{GJ} / \mathrm{MWh}$, whereas coal thermal power plants had the value of $10.48 \mathrm{GJ} / \mathrm{MWh}$ [9]. In the U.S.A., the average carbon intensity of coal power plants, natural gas power plants and natural gas CCPPs were $0.915 \pm 0.0008,0.5494 \pm 0.0011$ and 0.436 $\pm 0.0014 \mathrm{kgCO}_{2} / \mathrm{kWh}$, respectively [8], which is in line with the results in Thailand. Due to the higher thermal efficiency and lower environmental impact than other 
types of fossil fuel power plants, CCPPs are attractive in the power generation field. Energy use improvement can contribute in both energy and environmental aspects.

An exergy analysis is a potential tool for the energy efficiency improvement of many energy engineering applications [13]. Exergy is the maximum work or available work that can be obtained from different forms of energy in relation to a given environment [14]. Exergy analysis applies the first and second laws of thermodynamics to determine the maximum performance of the system and identify the main plant component of exergy destruction to determine potential performance improvement opportunities of power plants. Studies regarding the application of exergy analysis have been conducted to determine energy efficiency improvement potential. I. H. Aljindi performed energy and exergy analyses of a steam power plant in Jordan. The system components include boiler pump heaters, turbines and condensers. The study revealed that the maximum exergy destruction occurred in the boiler system, followed by the turbine and the forced draft fan condenser at 77\%, 13\%, and $9 \%$, respectively. The exergy destruction in a boiler system can be reduced by preheating the combustion air and reducing the air-fuel ratio [15]. S. C. Kamate et al. applied the exergy method to analyze the optimal steam inlet condition for the turbine in a cogeneration power plant [16]. R. Saidur et al. performed energy and exergy analyses of industrial boilers in Malysia and found that the combustion chamber is the major contributor for exergy destruction, followed by the heat exchanger [17]. An energy analysis of gas turbines with an air bottoming cycle was conducted by M. Ghazikhani et al. The result showed that the regenerator has the largest contribution in the exergy destruction of the air bottoming cycle, and the recovery of the exhaust exergy can increase the cycle performance [18]. The exergy and greenhouse gas emissions analyses of an integrated Organic Rankine Cycle (ORC) with a biomass combustor for different cases of operation was performed by F. A. Al-Sulaiman et al. The result showed that 1) the main two sources of exergy destruction were the biomass combustor and the ORC evaporator, and 2) the tri-generation (power, heat, and cooling) case can increase the exergy efficiency and, consequently, considerably reduce the carbon intensity [19].

For CCPPs, the exergo-environmental optimization of the Heat Recovery Steam Generator (HRSG), which is an important component and connection between the gas turbine and steam turbine cycles of a CCPP, was estimated through energy and exergy analyses. The results showed that for the given HRSG, most exergy destruction occurred in the high-pressure evaporator, and increasing the HRSG inlet gas temperature up to $650^{\circ} \mathrm{C}$ could increase the thermal and exergy efficiencies of the cycles [20].

In this study, the energy and carbon intensities of natural gas CCPPs in Thailand were analyzed. The results were compared to other studies. Moreover, exergy analysis of the plant components, including the HRSG and steam turbines, was conducted to analyze the energy improvement potential.

\section{Methodology}

To evaluate the energy and carbon intensity, the data of three natural gas CCPPs during 2013 - 2014 were collected and calculated. The energy intensity was calculated based on the data of energy used in the sample power plants, and the carbon intensity was calculated based on the IPCC guidelines for national greenhouse gas inventories [21]. The scope of emissions in this research includes direct (scope 1) and indirect (scope 2) emission sources. Moreover, the data of the processes in the plant analysis were also collected to perform the exergy analysis.

Three sample CCPPs with a total capacity of 1,648 MW (1,468 MW, $90 \mathrm{MW}$ and $90 \mathrm{MW}$ ) were considered in this research. The evaluation indicators and calculation methodology are detailed in the following section.

\subsection{Energy Intensity}

The energy intensity is the total energy consumption per unit of energy generated. Energy intensity can be expressed as follows:

$$
E I=\frac{E C}{P}
$$

where $E I$ is the energy intensity $(\mathrm{GJ} / \mathrm{MWh}), E C$ is the total energy consumption (GJ), and $P$ is the total power generated (MWh).

The total energy consumption is defined as a product of activity and net calorific values. The activity data include the amount of fuel consumed and the amounts of purchased electricity and steam. EC can be calculated as follows:

$$
E C=\sum(A D \times N C V)
$$

where $A D$ is the activity data (unit), and $N C V$ is the net calorific value (GJ/unit of activity).

\subsection{Carbon Intensity}

This research considered two sources of carbon dioxide emissions that were mentioned above. The emissions $\left(\mathrm{E}_{\mathrm{CO} 2}\right)$ can be expressed by the product of activity and the carbon dioxide emission factor as follows:

$$
E_{\mathrm{CO}_{2}}=\mathrm{AD} \times E \mathrm{~F}
$$

where $A D$ is the activity, and $E F$ is the carbon dioxide emission factor $\left(\mathrm{kgCO}_{2}\right.$ /unit of activity). The activity data include the amount of fuel consumed in the case of direct emissions as well as the amount of purchased electricity and steam in the case of indirect emissions.

The total carbon dioxide emission is defined by direct and indirect carbon dioxide emissions as follows:

$$
E_{\mathrm{CO}_{2, \text { total }}}=E_{\mathrm{CO} 2 \text {,direct }}+E_{\mathrm{CO} 2 \text {,indirect }}
$$

where $E_{\mathrm{CO}_{2, \text { total }}}$ is the total carbon dioxide emission $\left(\mathrm{kgCO}_{2}\right), E_{\text {co2, direct }}$ is the direct carbon dioxide emission caused by fossil fuel combustion in the plants, and 
$E_{C O 2, \text { indirect }}$ is the indirect carbon dioxide emission caused by using electricity and steam from outside the plants.

The carbon intensity is the carbon emission per unit of electricity generated. It can be expressed as the following equation:

$$
C I=\frac{E_{C O_{2, t o t a l}}}{P}
$$

where $C I$ is the carbon intensity $\left(\mathrm{kgCO}_{2} / \mathrm{kWh}\right), E_{C O_{2, \text { total }}}$ is the total carbon dioxide emissions, and $P$ is the total electricity generated.

\subsection{Exergy Analysis}

An exergy analysis is a potential tool in the analysis of design and performance improvement of power plants. The exergy balance equation for a control volume system can be presented as follows:

$$
\begin{gathered}
\dot{E} x_{Q}+\sum_{i} \dot{m}_{i} e x_{i}=\sum_{e} \dot{m}_{e} e x_{e}+\dot{E} x_{W}+\dot{E} x_{D} \\
e x=\left(h-h_{0}\right)-T_{0}\left(s-s_{0}\right)
\end{gathered}
$$

where $E x_{Q}$ is the exergy of the heat transfer rate $(\mathrm{kJ} / \mathrm{s})$, $\dot{E} x_{W}$ is the exergy rate of work $(\mathrm{kJ} / \mathrm{s}), E x_{D}$ is the exergy destruction rate $(\mathrm{kJ} / \mathrm{s})$, ex is the specific exergy $(\mathrm{kJ} / \mathrm{kg})$, $\dot{m}$ is the mass flow rate $(\mathrm{kg} / \mathrm{s}), h$ is the specific enthalpy $(\mathrm{kJ} / \mathrm{kg}), s$ is the specific entropy $(\mathrm{kJ} / \mathrm{kg}), T$ is temperature $(\mathrm{K}), i$ is the inlet, $e$ is the outlet, and 0 is the ambient condition.

The reference conditions used in this study were $P_{0}=$ 1.01 bar and $T_{0}=298.15 \mathrm{~K}$.

Figure 1 presents the schematic diagram of the sample CCPP. The combined cycle facility consists of one gas turbine (GT), combustion chamber (CC), air compressor (AC), HRSG, gas GT air cooler condenser and cooling tower, two generators(Gs) and three steam turbines (STs). In this research, the exergy analysis was performed with the HRSG, high pressure steam turbine (HP ST), intermediate pressure steam turbine (IP ST) and low pressure steam turbine (LP ST).

\subsubsection{Heat recovery steam generator (HRSG)}

The exergy destruction rate of the HRSG ( $\left.\dot{\mathrm{Ex}}_{\mathrm{D}, \mathrm{HRSG}}\right)$ can be calculated as follows:

$$
\dot{E} x_{D, H R S G}=\sum \dot{E} x_{H R S G, i}-\sum \dot{E} x_{H R S G, e}
$$

where $\dot{E} x_{D, H R S G}$ is the exergy destruction rate $(\mathrm{kW})$, $\sum E x_{H R S G, i}$ is the total exergy inflow rate $(\mathrm{kW})$, and $\sum E x_{H R S G, e}$ is the total exergy outflow rate $(\mathrm{kW})$.

The exergy efficiency of the HRSG $\left(\psi_{H R S G}\right)$ can be calculated as follows:

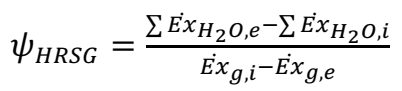

where $E x_{H R S G}$ is the exergy rate of the HRSG $(\mathrm{kW})$, $E x_{\mathrm{H}_{2} \mathrm{O}, e}$ is the exergy rate of water or steam $(\mathrm{kW})$, and
$E x_{g}$ is the exergy rate of gas $(\mathrm{kW})$. The subscript $i$ refers to the inlet and $e$ refers to the outlet.

\subsubsection{Steam turbine (ST)}

The exergy destruction rate of ST $\left(\dot{E} x_{D, S T}\right)$ can be calculated as follows:

$$
\dot{E} x_{D, S T}=\sum \dot{E} x_{S T, i}-\sum \dot{E} x_{S T, e}-\dot{W}_{S T}
$$

The exergy efficiency of ST $\left(\psi_{S T}\right)$ is as follows:

$$
\psi_{S T}=\frac{\dot{W}_{S T}}{\sum E x_{S T, i}-\sum E x_{S T, e}}
$$

where $\sum \dot{E} x_{S T, i}$ is the total exergy inflow rate of steam into the $\mathrm{ST}(\mathrm{kW}), \sum E x_{S T, e}$ is the total exergy outflow rate of steam from the ST $(\mathrm{kW})$, and $\dot{W}_{S T}$ is thework obtained from the ST $(\mathrm{kW})$.

\begin{tabular}{|c|c|c|}
\hline Component & & Equation \\
\hline \multirow{2}{*}{ HRSG } & $\dot{E} x_{D}$ & $\begin{array}{l}\left(\dot{\mathrm{E} x_{1}}+\dot{\mathrm{E}} \mathrm{x}_{2}+\dot{\mathrm{E} x_{3}}+\dot{\mathrm{E}} \mathrm{x}_{4}+\dot{\mathrm{E}} \mathrm{x}_{5}\right)- \\
\left(\dot{\mathrm{E} x_{6}}+\dot{\mathrm{E}} \mathrm{x}_{7}+\dot{\mathrm{E}} \mathrm{x}_{8}+\dot{E} \mathrm{Ex}_{9}+\dot{\mathrm{E}} \mathrm{x}_{10}\right)\end{array}$ \\
\hline & $\psi$ & 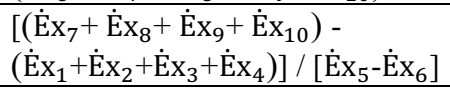 \\
\hline \multirow{2}{*}{ HP ST } & $\dot{\mathrm{Ex}} \mathrm{D}_{\mathrm{D}}$ & $\dot{\mathrm{E}} \mathrm{x}_{11}-\dot{\mathrm{E}} \mathrm{x}_{15}-\dot{\mathrm{W}}_{\mathrm{HP}, \mathrm{ST}}$ \\
\hline & $\psi$ & $\dot{\mathrm{W}}_{\mathrm{HP}, \mathrm{ST}} /\left(\dot{\mathrm{Ex}}_{11}-\dot{\mathrm{Ex}}_{15}\right)$ \\
\hline \multirow{2}{*}{ IP ST } & $\dot{\mathrm{E}} \mathrm{x}_{\mathrm{D}}$ & $\left(\dot{\mathrm{E}} \mathrm{x}_{12}+\dot{\mathrm{E}} \mathrm{x}_{13}\right)-\dot{\mathrm{E}} \mathrm{x}_{16}-\dot{\mathrm{W}}_{\mathrm{IP}, \mathrm{ST}}$ \\
\hline & $\psi$ & $\dot{\mathrm{W}}_{\mathrm{IP}, \mathrm{ST}} /\left[\left(\dot{\mathrm{Ex}}_{12}+\dot{\mathrm{E}} \mathrm{x}_{13}\right)-\dot{\mathrm{Ex}} \mathrm{x}_{16}\right]$ \\
\hline \multirow{2}{*}{ LP ST } & $\dot{\mathrm{E}} \mathrm{x}_{\mathrm{D}}$ & $\dot{\mathrm{E}} \mathrm{x}_{14}-\left(\dot{\mathrm{Ex}}_{17}+\dot{\mathrm{E}} \mathrm{x}_{18}\right)-\dot{\mathrm{W}}_{\mathrm{LP}, \mathrm{ST}}$ \\
\hline & $\psi$ & $\dot{\mathrm{W}}_{\mathrm{LP}, \mathrm{ST}} /\left[\dot{\mathrm{Ex}}_{14}-\left(\dot{\mathrm{Ex}}_{17}+\dot{\mathrm{E} \mathrm{x}_{18}}\right)\right]$ \\
\hline
\end{tabular}

According to equations 8 to 11 , the exergy destruction and exergy efficiency of the HRSG and each ST can be calculated by the equations in Table 1 . The subscript numbers in the equations refer to the schematic diagram in Figure 1.

Table 1. Exergy equation of each component.

\section{Result and Discussion}

\subsection{Energy Intensity}

The average energy intensity of the three sample CCPPs are illustrated in Figure 2. The result showed an overall average energy intensity of $7.995 \mathrm{GJ} / \mathrm{MWh}$. The major source of energy consumption was the natural gas combustion process, which was equal to $99.97 \%$ and $99.80 \%$ of the total energy consumption in 2013 and 2014, respectively. Compared with other research on energy intensity for combined cycles with natural gas fuel, it was observed that the energy intensity of this study was slightly lower than the other research $[9,12]$, as shown in Table 2.

\subsection{Carbon Intensity}

The carbon intensity of three sample CCPPs was evaluated, and the results of 2013 and 2014 are demonstrated in Figure 2. The average carbon intensity 
was $0.436 \mathrm{kgCO}_{2} / \mathrm{kWh}$. The major source of carbon emissions was the natural gas combustion process, which accounted for $99.67 \%$ and $99.55 \%$ in 2013 and 2014, respectively. Compared with other research on carbon intensity for combined cycles with natural gas fuel, it was observed that the carbon intensity of this study was in the same range as other research [7-8], as shown in Table 2.

A comparison of energy intensity and carbon intensity of natural gas CCPPs in this research with the values of other technologies and fuel types from other research studies is shown in Table 2 [7-9, 12]. The result illustrates that the CCPPs in this study were operated with relatively high energy efficiencies to present. However, the reduction potential in terms of energy and carbon intensity can be assessed by determining the energy efficiency improvement potential through exergy analysis.

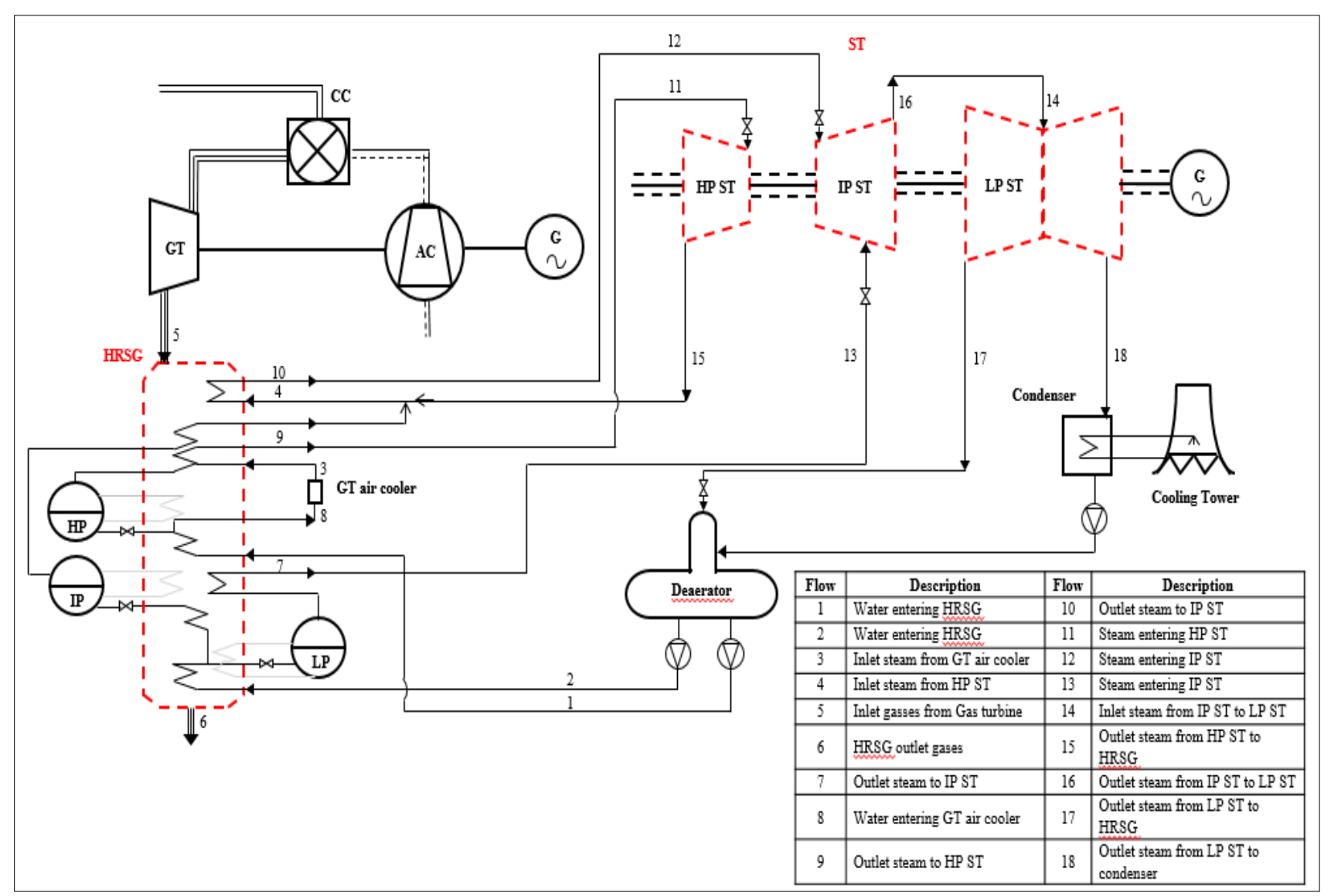

Figure 1. Schematic diagram of the combined cycle power plants.

Table 2. Comparison of carbon intensity and energy intensity.

\begin{tabular}{|l|l|c|c|c|}
\hline \multirow{5}{*}{ Technologies } & \multicolumn{1}{|c|}{ Fuel types } & $\begin{array}{c}\text { Energy Intensity } \\
(\mathrm{GJ} / \mathrm{MWh})\end{array}$ & $\begin{array}{c}\text { Carbon Intensity } \\
\left(\mathrm{kgCO}_{2} / \mathrm{kWh}\right)\end{array}$ & References \\
\hline \multirow{5}{*}{ Combined cycle } & \multirow{3}{*}{ Natural Gas } & 7.995 & 0.436 & This research \\
\cline { 3 - 5 } & & - & 0.426 & {$[7]$} \\
\cline { 3 - 5 } & & - & 0.436 & {$[8]$} \\
\cline { 3 - 5 } & & 7.970 & - & {$[9]$} \\
\cline { 2 - 5 } & Natural Gas and Diesel & 9.037 & - & {$[12]$} \\
\hline \multirow{3}{*}{ Thermal } & Natural Gas Fuel oils and Diesel & - & 0.469 & {$[7]$} \\
\cline { 2 - 5 } & Natural Gas and Fuel oils & - & 0.600 & {$[7]$} \\
\cline { 2 - 5 } & Coal/Lignite & - & 0.914 & {$[7]$} \\
\hline Gas turbine & Diesel & 10.48 & - & {$[9]$} \\
\hline Diesel engine & Diesel & - & 0.970 & {$[7]$} \\
\hline
\end{tabular}




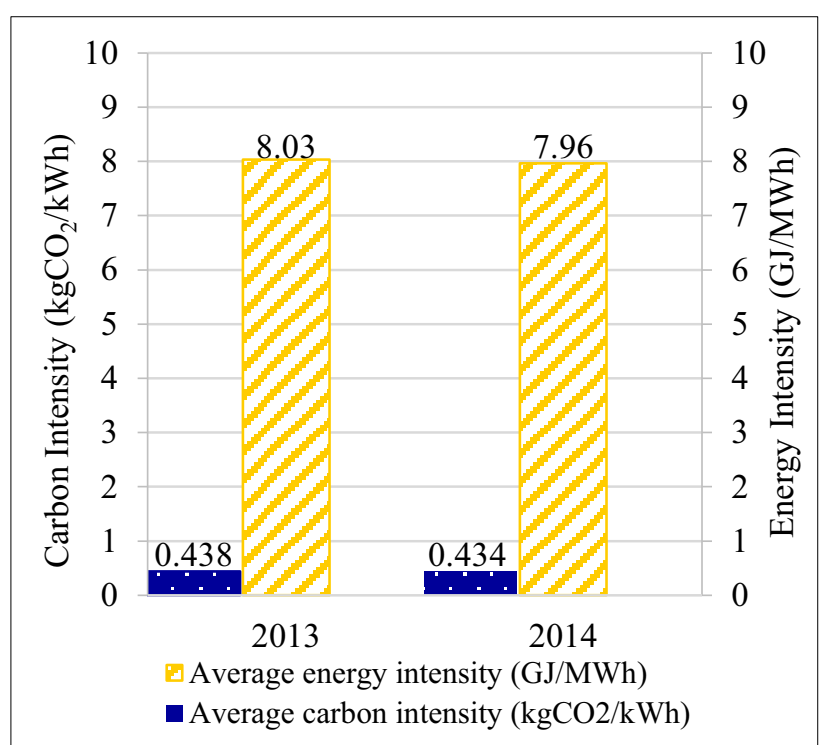

Figure 2. Energy and Carbon intensity of combined cycle power plants.

\subsection{Exergy Analysis}

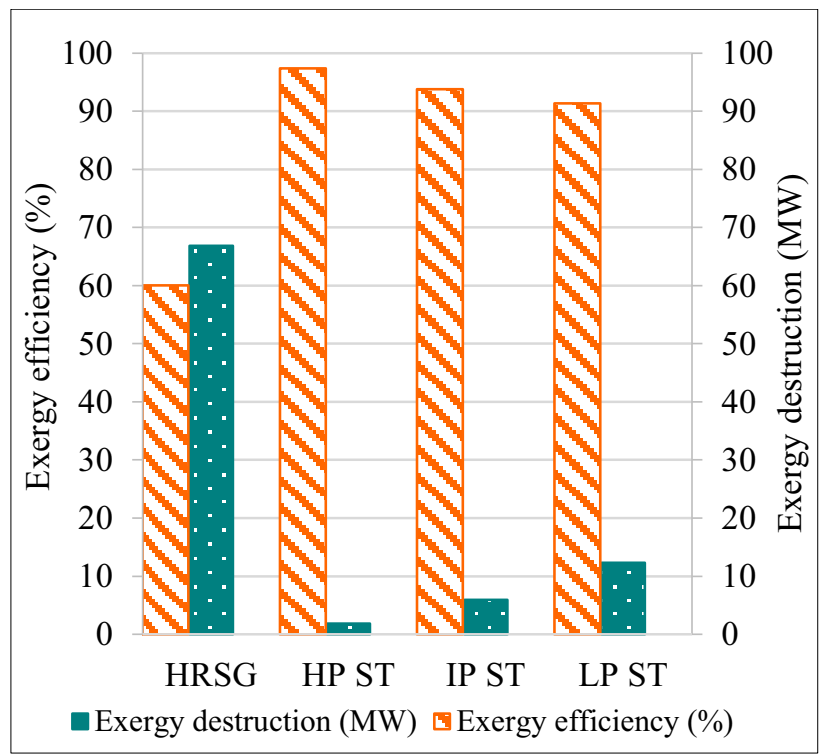

Figure 3. Exergy destruction rate and efficiency.

The exergy destruction and efficiency of the HRSG and three steam turbines were analyzed by the equations in Table 1 using the reference pressure and temperature of $1.01 \mathrm{bar}$ and $298.15 \mathrm{~K}$, respectively. The results are shown in Figure 3. The result revealed that the HRSG was the major contributor for exergy destruction, followed by the LP ST, IP ST, and HP ST, with values of 66.88 MW, $12.33 \mathrm{MW}, 5.94 \mathrm{MW}$, and $1.88 \mathrm{MW}$, respectively. In addition, the HP ST had the highest exergy efficiency, followed by the IP ST, LP ST and HRSG, with values of $97 \%, 94 \%, 91 \%$, and $60 \%$, respectively. This indicates that the HRSG has more energy efficiency improvement potential than the steam turbines. The steam turbines had a high exergy efficiency of more than $90 \%$, which suggests that the loss of available energy is less than $10 \%$. However, the loss of available energy in the HRSG was approximately $40 \%$ of the total inflow available energy (exergy). One approach that can be used to improve the thermal and exergy efficiencies of HRSG is to increase the HRSG inlet gas temperature [20]. The improvement of performance of this cycle will consequently reduce the energy and carbon intensities.

\section{Conclusion and recommendation}

Natural gas combined-cycle power plants provide the lowest carbon and energy intensities compared to other technologies and other types of fossil fuels. This research aimed to evaluate the energy and carbon intensities of natural gas combined-cycle power plants and to determine the potential to reduce energy and carbon intensity. According to our findings, the average energy and carbon intensities of combine-cycle power plants in Thailand were $7.995 \mathrm{GJ} / \mathrm{MWh}$ and $0.436 \mathrm{~kg} \mathrm{CO} / \mathrm{kWh}$, respectively. The potential of carbon intensity and energy intensity reduction was determined by an exergy analysis. The results of the exergy analysis revealed that the HRSG had the greatest exergy destruction contribution due to the wide range of temperature, followed by the LP ST and IP ST, whereas the HP ST produced the lowest exergy destruction. In addition, the HP ST had the highest exergy efficiency, followed by the IP ST, LP ST and HRSG. The exergy destruction rate of the HRSG was $66.88 \mathrm{MW}$, with an exergy efficiency of $60 \%$. Therefore, improving the thermal efficiency of the HRSG can improve the efficiency of power plants. One approach to improve the thermal and exergy efficiencies of the HRSG is to increase the HRSG inlet gas temperature. Improving the performance will result in lower energy use and emission reduction.

\section{Acknowledgement}

This research has been supported by National Research University Project, Office of Higher Education Commission (WCU-58-015-EN).

\section{References}

1. Office of Natural Resources and Environmental Policy and Planning, climate, change of model scheme 2015 2050, (2015)

2. Joint Graduate School of Energy and Environment, Second National Communication, (2010)

3. Energy Policy and Planning Office, Ministry of Energy,Energy Statistics of Thailand 2014, (2013)

4. Department of Alternative Energy Development and Efficiency, The analysis of indicators of energy efficiency in the steel industry, (2015)

5. S. Juntueng, S. Towprayoon, S. Chiarakorn, Resour Conserv Recy, 87, 46-56, (2014)

6. P. Kanchanapiya, N. Limphitakphong, C. Pharino, O. Chavalparit, Greenhouse Gas Measurement and Management, 4, 161-177, (2014)

7. S. Patumsawad, Carbon Intensity of Power Industry (Fossil fuel power plant), (2010) 
8. J. Gouw, J. A. d., D.D. Parrish, G.J. Frost1, M. Trainer, Reduced Emissions of $\mathrm{CO}_{2}, \mathrm{NO}_{x}$ and $\mathrm{SO}_{2}$ from U.S. Power Plants Due to the Switch from Coal to Natural Gas with Combined CycleTechnology, (2014)

9. Electricity Generating Authority of Thailand, SEPA Conference 2014 : Driving for Excellence, (2014)

10. Electricity Generating Authority of Thailand, National Grid, (2015)

11. Y. A. Cengel, M. A. Boles, Thermodynamics : an engineering approach 7st ed. (Mcgraw-Hill, 2011)

12. M. Nyberg, Thermal efficiency of gas-fired generation in California :2014 updated, (2014)

13. I. Dincer, M. A. Rosen, Exergy, environment and sustainable development (Elsevier Sci., 2013)

14. T. J. Kotas, The Exergy Method of Thermal Plant Analysis (Paragon Publishing, 2012)
15. I. H. Aljindi, Appl Therm Eng, 29, 324-328 (2009)

16. S. C. Kamate, P. B. Gangavati, Appl Therm Eng, 29, 1187-1194, (2009)

17. R. Saidur, J. U. Ahamed, H. H. Masjuki, Energ Policy, 38, 2188-2197, (2010)

18. M. Ghazikhani, I. Khazaee, E. Abdekhodaie, Energy, 72, 599-607, (2014)

19. F. A. Al-Sulaiman, F. H. amdullahpur, I. Dincer, Appl Therm Eng, 31, 439-446, (2011)

20. A. G. Kaviri, M. N. M. Jaafar, T. M. Lazim,H. Barzegaravval, Energ Convers Manage,67, 27-33, (2013)

21. IPCC, IPCC Guidelines for National Greenhouse Gas Inventories Volume 2: Energy, (2006) 